\title{
Quantification and Distribution of Polynuclear Aromatic Hydrocarbons (PNAs) in Surface Waters in the Vicinity of Kokori Oil Field, Nigeria
}

\section{EMOYAN, ONOS ONORIODE}

\author{
Department of Chemistry, Delta State University, P.M.B 1 Abraka, Nigeria. \\ onostica_pub@yahoo.com +2348037410599
}

\begin{abstract}
The distribution pattern and sources of sixteen PANs listed as priority pollutants were investigated in eight composite water samples using Gas Chromatography (GC) with a Hawlett-Packard model 6890 with $30 \mathrm{~m} \times 0.28$ capillary column. Analytical observation of the percentage distribution of PNAs concentration in the study area show that $\mathrm{SS}_{\mathrm{Y}}(20.12 \%)>\mathrm{SS}_{\mathrm{X}}(16.75 \%)>\mathrm{SS}_{\mathrm{Z}}(16.01 \%)>\mathrm{SS}_{\mathrm{T}}(14.43 \%)>\mathrm{SS}_{\mathrm{W}}(13.24 \%)>\mathrm{SS}_{\mathrm{U}}(12.06 \%)>\mathrm{SS}_{\mathrm{V}}(6.84 \%)>\mathrm{SS}_{\mathrm{A}}(0.55$ $\%$ ). The observed distribution of genotoxic (Gen.) and carcinogenic (Car.) PNAs and other PNAs in the study area show that the Gen. and Car PNAs recorded $29.58 \%$ over other PNAs with $70.42 \%$. The percentage distribution of low PNAs/high PNAs and ratio analysis show that this sources are petrogenic and pyrogenic but dominated with petrogenic PNAs@ @ JASEM
\end{abstract}

Polynuclear aromatic hydrocarbons (PNAs) are fused-ring compounds that enter natural waters via wastewater effluents from coke and petroleum refining industries, accidental spills and leakage, rainwater runoff from high way or from intentional disposal. (Baumard et al., 1999), others are burnt agricultural waste, motor vehicle exhaust, cigarette smoke, asphalt road and roofing operations, (Berko, 1999). PNAs exhibit toxic characteristic at low concentrations and several have been listed as priority pollutants to be monitored in industrial effluents, natural waters, (Watts, 1997). PNAs are generally insoluble in water but can be readily solubilised in organic acids. They are therefore adsorbed on particulates and any oil contaminant that may be present in water, sediment and soil because of their lipophilic, high boiling point and hydrophobic properties (Lundstedt, et al., 2003). Their effects and fate in nature are of great environmental and human health concern due to their widespread occurrence, persistence in aquatic ecosystem and carcinogenic properties as well as having cardiovascular, bone marrow and liver toxicity, (IPCS, 1998 and Muller, 1997). PNAs are ubiquitous in the environment being present in air (Berko, 1999), soil (Wcislo 1998), water (WHO) and food such as cereals, grains, flour, bread, vegetable, fruits, fish, meat, processed or picked food and contaminated cow and human breast milk, (FSA, 2002; Falco, et al., 2003 and Azza, 2006). The need to monitor PNAs concentrations in aquatic environment around oil installation is imperative because there are no data on PNAs status around oil installations and the attendant human and environmental effect of these persistent and organic pollutants (POPs).

\section{MATERIALS AND METHODS}

\section{Study area}

The study area falls within the Kokori oil-field and is located between latitude $6^{\circ} 02^{\prime}$ to $6^{\circ} 05^{\prime} \mathrm{N}$ and longitude $5^{\circ} 36^{\prime}-5^{\circ} 42^{\prime} \mathrm{E}$. The oil wells have been in operations for over 30 years. The study area covers an approximate area of $2 \mathrm{~km}^{2}$ with access road made of asphalt connecting various oil well head. Well 13, 34, 35 and 13 are in a fenced land measuring about 200 sq feet. Also, well 143637 in a fenced land measuring 200sq feet. Anthropogenic activities in the area include: oil/gas extraction (with oil well-heads and flow station), and peasant agriculture. According to UNDP (2006), the rainfall pattern is the characteristics of the rainforest zone with mean annual rainfall of $3000 \mathrm{~mm}$. Temperature are high and fairly constant throughout the year. Average monthly temperature for the warmest months (February to April) ranged from $28^{\circ} \mathrm{C}$ to $33^{\circ} \mathrm{C}$ while the average monthly temperature for the coolest months (June September) ranged between $21^{\circ} \mathrm{C}$ and $23^{\circ} \mathrm{C}$.

\section{Sampling}

Samples were collected in the month of June 2007. All sample containers were thoroughly washed with laboratory grade phosphate detergent and then rinsed with deionized water. The containers were then heated for about 30 minutes until dryness. Samples were collected in a litre amber glass bottle with Teflon-lined screw-cap, $5 \mathrm{ml}$ of $1: 1 \mathrm{HCl}$ acid was added. Samples were transferred from sample station in container with ice chest and stored at $\leq$ $4^{\circ} \mathrm{C}$ for 5 days before extraction and analysis as recommended by OIEWG (1999) and APHA, (1998).

\section{Analysis}

Samples for PNAs analysis were extracted with methylene chloride, dried with anhydrous $\mathrm{Na}_{2} \mathrm{SO}_{4}$ and solvent exchanged into hexane. Clean up and fractionation was done using silica gel permeation chromatography. Final extracts after concentration using a rotary evaporator was packed in $2 \mathrm{~mL}$ GC vials and analysed with a gas chromotograph (GC), Hawlett-Packed model 6890 with a $30 \mathrm{~m}$ x $0.25 \mathrm{~mm}$ capillary column (Crosslinked 50\% pH siloxane) and a flame ionization detector. GC column conditions: Column made up of 5\% pms (100/120 
mesh) coated with $3 \%$ OV-17 packed in a $1.8+$ $2 \mathrm{~mm} 10$ glass column with Helium carrier gas at $40 \mathrm{~mL} / \mathrm{min}$. flow rate. Column temperature held at $100^{\circ} \mathrm{C}$ for $4 \mathrm{~min}$, there programmed at $8^{\circ} \mathrm{C} / \mathrm{min}$ to a final hold at $280^{\circ} \mathrm{C} . \mathrm{H}_{2}$ and Air gas were used to light up the fid. PNAs levels was accomplished using a seven-point external standard (APHA, 1998). The standard curves were linear, with correlative confluent for the investigated PNAs ranging between 0.997 and 0.999 , no external standards were employed in the qualification using the GC. The analysis was done at Thermostell laboratory, Effurun Warri.

\section{RESULTS AND DISCUSSION}

Analyses of result show that, there is high concentration of PANs in the study area with mean values ranging from 0.2309 to $1.0468 \mathrm{mgL}^{-1}$ as shown in Table 1 . The cumulative results also indicated that the total concentration of PNAs in the various sample station is in the order of $\mathrm{SS}_{\mathrm{Y}}>$ $\mathrm{SS}_{\mathrm{X}}>\mathrm{SS}_{\mathrm{Z}}>\mathrm{SS}_{\mathrm{T}}>\mathrm{SS}_{\mathrm{W}}>\mathrm{SS}_{\mathrm{U}}>\mathrm{SS}_{\mathrm{V}}>\mathrm{SS}_{\mathrm{A}}$. The results further reveal that $\mathrm{SS}_{\mathrm{XYZ}}$ has $52.88 \%$ of the total concentration in the study area while $\mathrm{SS}_{\mathrm{UVW}}$ has $32.14 \%$ with $\mathrm{SS}_{\mathrm{T}}$ and $\mathrm{SS}_{\mathrm{A}}$ having $14.43 \%$ and
$0.55 \%$ respectively. This shows that well- head 14 , 36 and 37 contributed more to the release of these contaminates in the study area. The mean concentration distribution of the sixteen PNAs listed as priority pollutant show that the 2 membered ring occupied the lowest $\%(9.7 \%)$ from the total PNAs concentration of $9.491 \mathrm{mgL}^{-1}$. Similarly, the 5 and 6 membered ring accounted for $9.70 \%$ and $12.46 \%$ respectively. While the 4 membered ring having $22.34 \%$, the 3 membered ring accounted for the highest \% (46.40\%). Investigation into the sources of PNAs have used the molecular ratio of some specific hydrocarbons (Soclo et al., 2000; Yunker et al., 2002; Lin, et al.; 2005 and Emoyan et al., 2008). From the computed Ant $/ 178$ ratio of 0.004 , flt/flt + pyr of 0.57 ; flu/pyr of 2.13 and phe/Ant of 1.03 reveal that petrogenic and pyrogenic source contributed to the distribution of these priority contaminant in the study area. However, the results show that low molecular weight hydrocarbon (LPNAs) accounted for 55.5\% while high molecular weight hydrocarbon (HPNAs) recorded $44.5 \%$, which is an indication that the sources of PNAs concentration in the study area is of petroganic dominance.

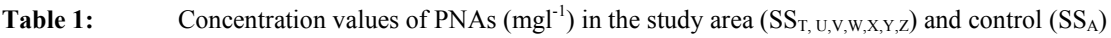

\begin{tabular}{lllllc}
\hline \multicolumn{1}{c}{ PNAs } & Mw & Ring & \multicolumn{1}{c}{ Range } & \multicolumn{1}{c}{ X/S } & P. Value \\
\hline Naphthalene (Nap) & 128.2 & 2 & $0-1.42$ & $0.863 \pm 0.5172$ & $>0.05$ \\
Acenaphthylene (Acy) & 152.2 & 3 & $0.215-1.215$ & $0.9011 \pm 0.4145$ & $>0.05$ \\
Acenaphthene (Ace) & 154.2 & 3 & $0-1.186$ & $0.7428 \pm 0.4979$ & $>0.05$ \\
Fluoren (Flu) & 166.2 & 3 & $0-1.525$ & $1.0468 \pm 0.4673$ & $>0.05$ \\
Phenathrene (Phe) & 178.2 & 3 & $0-1.213$ & $0.8714 \pm 0.5057$ & $>0.05$ \\
Anthrecene (Ant) & 178.2 & 3 & $0-1.561$ & $0.8421 \pm 0.5824$ & $>0.05$ \\
Fluoranthene (Fla) & 202.3 & 4 & $0-1.152$ & $0.6594 \pm 0.5245$ & $>0.05$ \\
Pyrene (Pyr) & 202.3 & 4 & $0-1.253$ & $0.4918 \pm 0.5570$ & $>0.05$ \\
Chrysene (Chr) & 228.3 & 4 & $0.017-1.212$ & $0.4745 \pm 0.5260$ & $>0.05$ \\
Benzo (a) anthracene (B[a]A) & 228.3 & 4 & $0.015-1.514$ & $0.4950 \pm 0.6020$ & $>0.05$ \\
Benzo (a) pyren (B[a]P) & 252.3 & 5 & $0.11-1.121$ & $0.2309 \pm 0.3732$ & $>0.05$ \\
Benzo (b) fluoranthen (B[b]F) & 252.3 & 5 & $0-1.451$ & $0.3938 \pm 0.5639$ & $>0.05$ \\
Benzo (k) fluoranthene (B[k]F) & 252.3 & 5 & $0-1.251$ & $0.2956 \pm 0.4377$ & $>0.05$ \\
Benzo (ghi) perylen (B[ghi]P) & 267.0 & 6 & $0-1.512$ & $0.3753 \pm 0.5107$ & $>0.05$ \\
Indeno (123-c) Pyren (I[123cd]P) & 276.3 & 6 & $0-1.612$ & $0.5411 \pm 0.6814$ & $>0.05$ \\
\hline Dibenzo (a,h) anthracen (D[ah]A) & 278.4 & 6 & $0-1.515$ & $0.2660 \pm 0.5106$ & $>0.05$ \\
\hline
\end{tabular}

Table 2: Comparison of the concentration of some selected PNAs in the study area with the Canadian and Netherlands guidelines for the protection of aquatic lives $\left(\mathrm{mgL}^{-1}\right)$

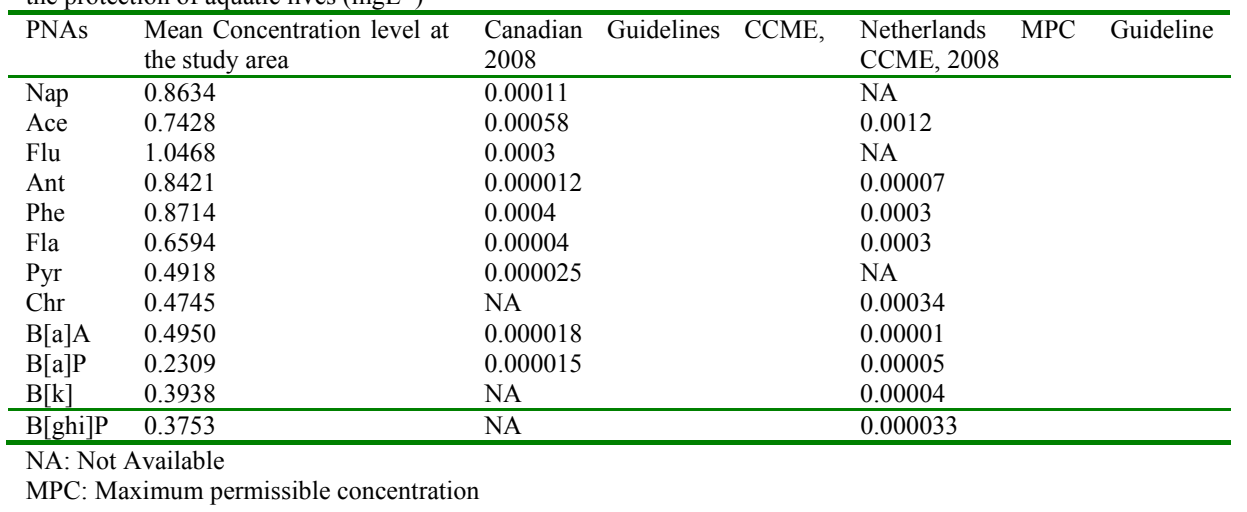

In a related development, the percentage distribution of Gen. and Car. PNAs (Chr, B[a]A,
$\mathrm{B}[\mathrm{a}] \mathrm{P}, \mathrm{B}[\mathrm{b}] \mathrm{F}, \mathrm{B}[\mathrm{k}] \mathrm{F}, \mathrm{B}[\mathrm{ahi}] \mathrm{P}, 1[123-\mathrm{cd}] \mathrm{P}$ and $\mathrm{D}[\mathrm{ah}] \mathrm{A}$ and other PNAs (Nap, Acy, Acc, flu, Flu, 
Phe, Ant, Fla and Pyr) (WHO/IPCS, 1998). In the study area reveal that the Gen. and Car. PNAs recorded $29.58 \%$ over other PNAs with $70.42 \%$. Analytical observation of the percentage distribution show that Gen. Car. PNAs concentration in the study area is of the order $\mathrm{SS}_{\mathrm{Y}}$ $(50.64 \%)>\mathrm{SS}_{\mathrm{U}}(47.17 \%)>\mathrm{SS}_{\mathrm{x}}(44.63 \%)>\mathrm{SS}_{\mathrm{Z}}$ $(37.14 \%) \mathrm{SS}_{\mathrm{A}}(25.66 \%)>\mathrm{SS}_{\mathrm{V}}(14.54 \%)>\mathrm{SS}_{\mathrm{T}}$ $(11.35 \%)>\mathrm{SS}_{\mathrm{W}}(5.50 \%)$ as shown in Figure 1. The high percentage of other PNAs (LPNAs with molecular weight $<228.2$, were $\operatorname{logKow}<5$ ) could be attributed to LPNAs being water soluble with low affinity for particulate adsorption (Mackay et al., 1992; CCME, 2008). Furthermore, the high percentage of other PNAs (LPNAs) in the study area reveals that petrogenic source contributed more to the release of PNAs into the study area.
Comparing the mean concentration values of some selected PNAs in the study area with International guidelines for the protection of aquatic lives as shown in Table II, show that the concentration ratio of the observed PNAs with these guidelines is well above 1:100. Result screening show that the oil well-head and the flare site recorded $99.45 \%$ of the total concentration while the control point accounted for $0.55 \%$.

Conclusion: Analyses of results show that, there is high percentage of PNAs in the study area when compared with International guidelines for the protection of aquatic ecosystem. The sources of these POPs are of patrogenic dominance as shown in the results.

Figure 1: Percentage Distribution of Genotoxic and Carcinogenic PNAs and other PNAs in the Study Areas.

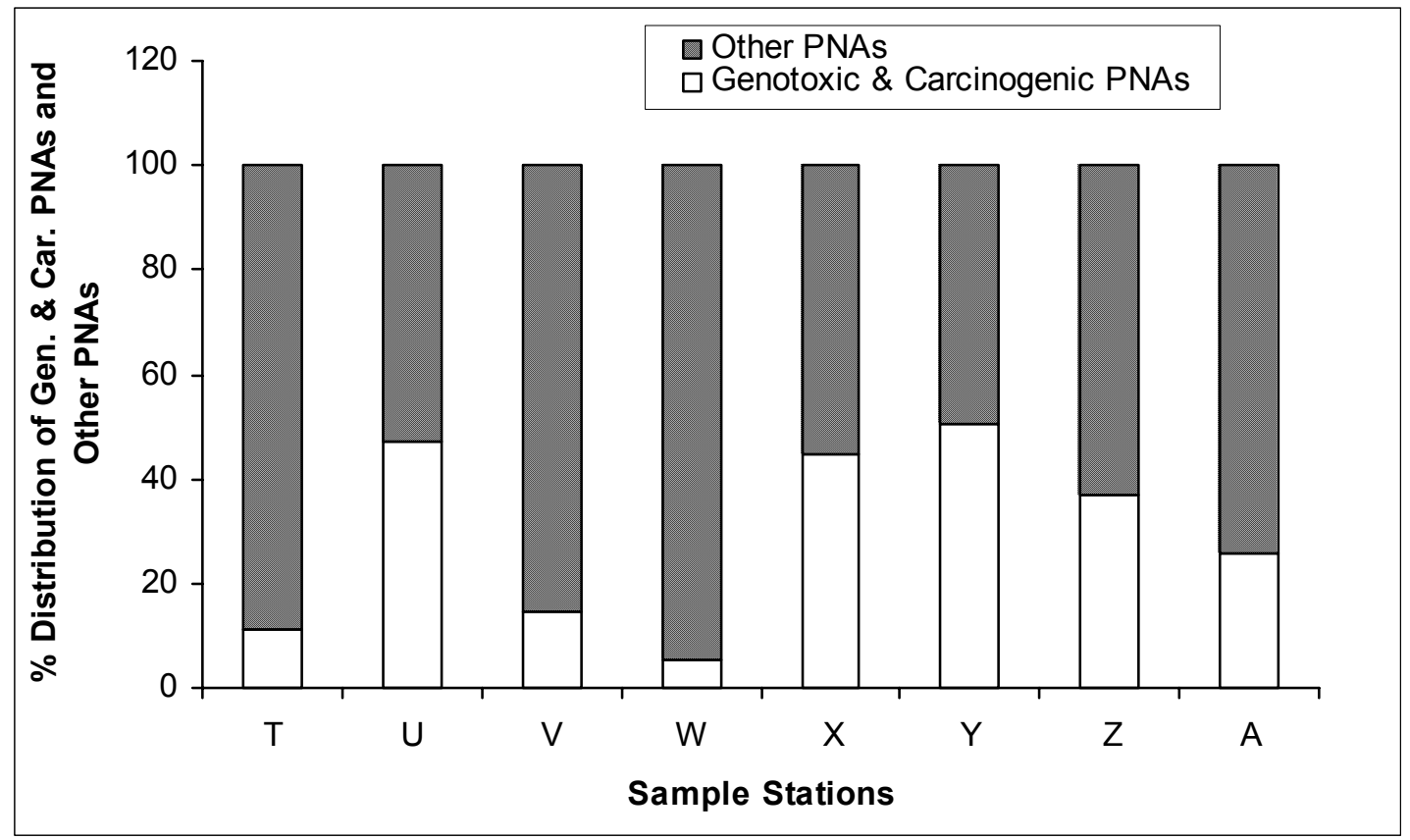

\section{REFERENCES}

APHA: Standard Methods for the Examination of Water and Wastewater, $20^{\text {th }}$ edition Publishers: American Public Health Association; American Water Works Association; Water Environment Federation (1998).

Azza, Z. (2006). Levels of Polyaromatic Hydrocarbons in Egyptian Vegetables and their Behaviour During Soaking in Oxidizing Agent Solutions. World J. of Agricultural Science 2(1) 90-94.

Baumard P; Budzinski H; Garrigues P; Dizer H; Hansen P.D. (1999). Polycyclic Aromatic Hydrocarbons (PAHs) in recent Sediments and Mussels (Mytilus edulis) from Western Baltic
Sea: Occurrence, Bioavailability and Seasonal Variations. Mar Environ. Res., 47,17-47.

Berko, H.N. (1999). Polycyclicaromatic Hydrocarbons (PAHs) in Australia, Environment Australia. 55.

CCME, (2008). Canadian Soil Quality Guidelines for the Protection of Environmental and Human Health: Benzo [a] Pyrene (1997). In: Canadian Environmental Quality Guidelines, 1999, Canadian Council of Ministers of the Environment, Winnipeg.

Emoyan O.O.; Agbaire P.O; Peretiemo-Clarke B.O. (2008) Distribution and Speciation of Polyaromatic Hydrocarbons (PAHs) in Soil Around Oil Well Heads in Delta State, Nigeria 
Proceedings of the $31^{\text {st }}$ International Conference of the Chemical Society of Nigeria (CSN) Delta-Chem 2008. 762-771.

Falco, G; Domingo J.L; Lobet J. M; Teixido A; Casas C; Muller L. (2003). PAHs in foods: Human Exposure through the Diet in Catalonia, Spain, J. Food Protection, 66, 2325231.

(FSA), Food Standard Agency of UK (2002). PAHs in the UK diet: 2000 Total Diet Study Samples. Food Survey Information Sheet No 31/02. UK: FSA.

IPCS, (1998). "Selected Non-heterocyclic Polycyclic Aromatic Hydrocarbons" Environmental Health Criteria 202, International Programme on Chemical Safety, WHO, Geneva.

Lin. D., T.U.Y; Zhu L. (2005). Concentrations and Health Risk of Polycyclic Aromatic Hydrocarbons in tea. Food and Chemical Toxiocology, 43: 41-48.

Lundstedt S; Haglund, P. Oberg, (2003). Degradation and Formation of Polycyclic Aromatic Compounds during Bioslurry Treatment of an Aged Gasworks Soils. Environ. Toxicol. Chem. 22, 1413-1420.

Mackay, D; Shiu, W.Y; Ma, K.C. (1992). Illustrated handbook of Physical-Chemical Properties and Environmental fate for Organic Chemicals: Polynuclear Aromatic Hydrocarbons, Polychlorinated Dioxins and Dibenzofurans. Chelsea, Michigan: Lewis Publishers.

Muller, P., (1997). Scientific Criteria Document for Multimedia Standards Development Polycyclic Aromatic Hydrocarbons (PAH); Part 1: Hazard
Identification and Dose-Response Assessment. Standard Development Branch, Ontario Ministry of Environment and Energy.

OIEWG (1999). Sampling Protocols and Analytical Methods for Determining Petroleum Products in Soil and Water. Ministry for the Environment Wellington 40.

Soclo H.H., Garrigues P., Ewald M. (2000) Origin of Polycyclic Aromatic Hydrocarbons in Coastal Marine Sediments: Case Studies in Cotonou (Benin) and Aquitaine (France) Areas, Marine Pollution Bulletin, Vol. 40, 387396.

UNDP (2006), Niger Delta Human Development Report. 229.

Watts, R.J. (1997). Hazardous Waste Sources. Pathways and Receptors. John Willey and Sons Inc. New York 201-203.

Wcislo E. (1998). Soil Contamination with Polycyclic Aromatic Hydrocarbons (PAHs) in Poland-a Review Polish J. of Environmental Studies 7, (5), 267-272.

WHO/IPCS, (1998). Environmental Health Criteria 202: Selected Non-Heterocyclic Polycyclic Aromatic Hydrocarbon. International Program on Chemical Safety, United Nations Environmental Program, World Health Organization. Geneva. 883.

Yunker M.B., Macdonald R.W., Vingarzan R., Mitchell R.H., Goyette D., and Sylvestre S. (2002) PAHs in the Fraser River Basin: a Critical Appraisal of Polycyclic Aromatic Hydrocarbons Ratios as Indicators of PAH Source and Composition, Organic Geochemistry, 33, 489-515. 